\title{
Self rated health: Is it as good a predictor of subsequent mortality among adults in lower as well as in higher social classes?
}

\author{
B Burström, P Fredlund
}

\begin{abstract}
Study objective-To analyse the predictive power of self rated health for mortality in different socioeconomic groups.

Design, setting, participants-Analysis of mortality rates and risk ratios of death during follow up among 170223 respondents aged 16 years and above in the Swedish Survey of Living Conditions 19751997 , in relation to self rated health stated at the interview, by age, sex, socioeconomic group, chronic illness and over time.

Main results-There was a strong relation between poor self rated health and mortality, greater at younger ages, similar among men and women and among persons with and without a chronic illness. The relative relation between self rated health and subsequent death was stronger in higher than in lower socioeconomic groups, possibly because of the lower base mortality of these groups. However, the absolute mortality risk differences between persons reporting poor and good self rated health were similar across socioeconomic groups within each sex. The mortality risk difference between persons reporting poor and good self rated health was considerably higher among persons with a chronic illness than among persons without a chronic illness. The mortality risk among persons reporting poor health was increased for shorter $(<2$ years) as well as longer $(10+$ years $)$ periods of follow up.

Conclusions-The results suggest that poor self rated health is a strong predictor of subsequent mortality in all subgroups studied, and that self rated health therefore may be a useful outcome measure. ( $F$ Epidemiol Community Health 2001;55:836-840)
\end{abstract}

Self rated health is a commonly used outcome measure in social epidemiology studies, where it has been found to be inversely associated with various aspects of social position, such as level of education, ethnicity and socioeconomic group. ${ }^{1-5}$ Studies of correlates of self rated health have found varying results concerning medical health, functional ability, physiological variables, symptoms, sociodemographic variables, social factors, behavioural factors and personality factors, and the clinical correlate of self rated health may be less evident than that of other measures such as longstanding illness. ${ }^{1}$
Nevertheless, since the first clear demonstration in $1982,{ }^{6}$ self rated health has repeatedly been found to be a strong predictor of subsequent mortality. ${ }^{7}$ Few, however, have investigated whether the strength of that predictive power is the same for different subgroups of the population and in different cultures. The association between self rated health and mortality may not be as strong for some groups as for others. This is becoming a more pressing question as interest mounts in investigating social inequalities in health also in low income countries, in which anomalies are surfacing. Studies in India, for instance have shown that poorer groups report less morbidity than would be expected from their mortality profile. $^{8}$ This could indicate that self rated health is context dependent, and raises the possibility of cultural and socioeconomic differences in perceptions or reporting of self rated health that might change its relation with subsequent mortality, throwing doubts on the validity of using self rated health for certain groups. For example, health problems may be voiced more loudly by wealthier groups, while poorer groups suffer in silence.

Most previous studies have been carried out on elderly subjects. However, studies that have also included younger adults ${ }^{45}{ }^{9-11}$ have found a predictive value of self rated health with respect to subsequent mortality. Most studies have found a stronger relation between self rated health and mortality among men than among women, ${ }^{7}$ but others have reported the opposite. ${ }^{5}$ One study concluded that perceived health levels mainly reflect underlying disease burden. ${ }^{12}$ However, little is known about how the relation between self rated health and mortality is modified by age, sex, social class and concurrent longstanding illness and over time.

The aim of this study was to investigate the predictive power of self rated health for mortality in different socioeconomic groups in the Swedish population, making use of a unique dataset that links survey response data to subsequent mortality during follow up.

\section{Methods}

Annual series of data from the Swedish Survey of Living Conditions (ULF) 1975-1997 were used, based on face to face interviews with a random sample representative of the Swedish population aged 16 years and over, comprising in all 170223 men and women. The nonresponse rate in these surveys have increased slightly over time and ranges between 15\%$20 \% .^{13}$ The internal non-response rate for specific questions is very low (for questions on self 
Table $1 A$ Prevalence (\%) of fair and poor health by age group (men and women)

\begin{tabular}{lcc}
\hline Age group & Fair health $\%$ & Poor health $\%$ \\
\hline $16-24$ & 8.6 & 1.1 \\
$25-34$ & 9.0 & 1.4 \\
$35-44$ & 10.9 & 2.1 \\
$45-54$ & 14.9 & 3.6 \\
$55-64$ & 23.2 & 6.8 \\
$65-74$ & 30.8 & 9.2 \\
$75-84$ & 34.2 & 10.9 \\
$85+$ & 35.7 & 11.1 \\
\hline
\end{tabular}

rated health and longstanding illness less than $0.1 \%$ ), as the survey uses personal interviews. Deaths occurring among these persons were obtained from the national cause of death register. A total of 21427 persons (11957 men and 9470 women) died during the follow up period 1975-1998. The follow up time of subjects varied from $0-20$ years (average 10 years), depending on the time of interview. In all there were 909394 person years of follow up for men and 972844 person years for women.

Mortality rates and rate ratios of the risk of death during the follow up period were analysed in relation to self rated health at the time of the interview. Self rated health was assessed from answers to the question: "How would you assess your health?" In the years 1975-1995 there were three response options to the question: "Is it good, bad or something in between?". In 1996 and 1997, there were five response options: "Very good, good, all right, bad, very bad". Respondents answering that they had good or very good health are the reference group; those answering that they had bad or very bad health are referred to as having "poor health", and those answering that their health was something in between good and bad are referred to as having "fair health".

Respondents were divided into five socioeconomic groups according to their occupation, using the scheme of Statistics Sweden. ${ }^{14}$ Persons who could not be classified according

Table $1 B$ Age standardised prevalence rates (\%) of responses on the question on self rated health, by socioeconomic group, men and women

\begin{tabular}{llllll}
\hline & \multicolumn{2}{l}{ Men } & & & \multirow{2}{*}{ Women } \\
\cline { 2 - 3 } \cline { 5 - 6 } Socioeconomic group & Fair health & Poor health & & Fair health & Poor health \\
\hline Higher non-manual & 10.1 & 1.9 & & 12.0 & 2.4 \\
Intermediate non-manual & 9.6 & 1.9 & & 11.8 & 2.2 \\
Lower non-manual & 12.2 & 2.6 & & 14.5 & 3.0 \\
Qualified manual & 16.2 & 4.4 & & 18.2 & 4.4 \\
Unqualified manual & 18.0 & 5.1 & & 20.4 & 5.2 \\
Others & 18.4 & 8.1 & & 19.8 & 4.8 \\
\hline
\end{tabular}

Table 2 Age specific absolute mortality rates (per 100 000), and rate ratio (RR) of death with $95 \%$ confidence intervals (CI) between respondents stating poor/good health, and fair/good health, by age group. Men and women aged 16 years and above, Sweden 1975-1998

\begin{tabular}{lllll}
\hline & \multirow{2}{*}{$\begin{array}{l}\text { Overall } \\
\text { mortality } \\
\text { rgate/100 } 000\end{array}$} & $\begin{array}{l}\text { Good } \\
\text { health }\end{array}$ & $\begin{array}{l}\text { Relative risk }(R R) \text { of mortality (with 95\% CI), } \\
\text { compared with respondents with good health }\end{array}$ \\
\hline Fair/good health & Poor/good health \\
\hline $6-24$ & 44 & 1.0 & $3.0(1.6,5.9)$ & $4.5(1.1,18.7)$ \\
$35-34$ & 53 & 1.0 & $3.3(2.3,4.8)$ & $10.3(6.3,16.9)$ \\
$45-54$ & 116 & 1.0 & $2.3(1.8,2.9)$ & $5.0(3.6,7.0)$ \\
$55-64$ & 255 & 1.0 & $2.1(1.8,2.5)$ & $5.4(4.4,6.5)$ \\
$65-74$ & 771 & 1.0 & $1.8(1.6,2.0)$ & $4.1(3.6,4.6)$ \\
$75-84$ & 1989 & 1.0 & $1.7(1.6,1.8)$ & $3.4(3.2,3.7)$ \\
$85+$ & 5370 & 1.0 & $1.6(1.5,1.6)$ & $2.5(2.4,2.6)$ \\
All ages & 13514 & 1.0 & $1.3(1.2,1.4)$ & $1.7(1.6,1.8)$ \\
& 1138 & 1.0 & $1.6(1.5,1.7)$ & $2.9(2.8,3.0)$ \\
\hline
\end{tabular}

to this scheme were grouped as "others". Respondents were distributed into socioeconomic categories as follows: higher nonmanual (11.8\%), intermediate non-manual (13.1\%), lower non-manual (13.3\%), qualified manual $(21.8 \%)$, unqualified manual workers $(29.6 \%)$ and "others" (10.4\%). Respondents stating that they had a longstanding illness that to some degree limited their working capacity or their daily activities were defined as having a limiting longstanding illness.

Absolute direct age standardised mortality rates were calculated using the European Standard Population. ${ }^{15}$ The rate ratio (RR) of death was calculated with $95 \%$ confidence intervals (CI) estimates using Cox regression analysis, ${ }^{16}$ adjusting for age as a continuous variable. The rate ratio of death of respondents with poor or fair health was compared with that of respondents stating good health at the time of interview, stratified by socioeconomic group. Similar analyses were done stratifying for limiting longstanding illness, and in different strata of follow up time ( $<2$ years, 2-4 years, 5-9 years, 10 years and more). The Wald $\chi^{2}$ statistic was used to assess statistical significance at the $5 \%$ significance level.

\section{Results}

Age specific prevalence rates of fair and poor health are shown in table $1 \mathrm{~A}$. Rates of less than good health increased with age. There was a socioeconomic gradient in the age standardised prevalence rates of fair and poor health among men and women (table 1B). Among men with a limiting longstanding illness $39.8 \%$ reported fair health and $29.2 \%$ poor health. Corresponding figures for women with a limiting longstanding illness were $45.1 \%$ and $30.4 \%$, respectively.

There was a strong relation between poor self rated health and risk of subsequent death among men and women. Compared with respondents who stated they had good health at the time of the interview, the crude rate ratio (RR) of death among men and women with poor health was 8.0 (95\% CI 7.7, 8.3). Respondents who stated they had fair health had a RR of death of 3.8 (95\% CI 3.6, 3.9), compared with those stating that they had good health, suggesting a dose-response relation between self rated health and the subsequent risk of death. Adjusting for age reduced the overall RR of death to 2.9 for respondents stating poor health and 1.6 for respondents stating fair health, in comparison with respondents stating good health at the time of the interview (table 2). Apart from a slightly higher crude mortality rate ratio among women with poor health that disappeared when adjusting for age, there were no significant differences between men and women.

There was a statistically significant increased risk of death in all age groups among persons reporting poor self rated health compared with those reporting good health, but the relation was modified by age (table 2 ). The mortality rate ratio between persons reporting poor versus good health was highest 
Table 3 Mortality rate ratio (RR) with 95\% confidence intervals (CI) among persons stating poor and fair health at the time of interview, compared with respondents stating good health among men and women in different socioeconomic groups (adjusting for age as a continuous variable)

\begin{tabular}{|c|c|c|c|c|c|c|}
\hline \multirow[b]{2}{*}{ Socioeconomic group } & \multicolumn{3}{|l|}{ Men } & \multicolumn{3}{|l|}{ Women } \\
\hline & $\begin{array}{l}\text { Good } \\
\text { health RR }\end{array}$ & $\begin{array}{l}\text { Fair health } \\
R R\end{array}$ & $\begin{array}{l}\text { Poor health } \\
\text { RR }\end{array}$ & $\begin{array}{l}\text { Good } \\
\text { health }\end{array}$ & Fair health & Poor health \\
\hline Higher non-manual & 1.0 & $\begin{array}{l}1.9(1.7 \\
2.2)\end{array}$ & $\begin{array}{l}3.7(3.2 \\
4.3)\end{array}$ & 1.0 & $\begin{array}{l}1.5(1.2 \\
1.8)\end{array}$ & $\begin{array}{l}3.1(2.5 \\
3.9)\end{array}$ \\
\hline $\begin{array}{l}\text { Intermediate } \\
\text { non-manual }\end{array}$ & 1.0 & $\begin{array}{l}1.8(1.6, \\
2.1)\end{array}$ & $\begin{array}{l}3.3(2.7 \\
3.9)\end{array}$ & 1.0 & $\begin{array}{l}1.8(1.5, \\
2.1)\end{array}$ & $\begin{array}{l}3.5(2.8 \\
4.4)\end{array}$ \\
\hline Lower non-manual & 1.0 & $\begin{array}{l}2.2(1.9 \\
2.5)\end{array}$ & $\begin{array}{l}3.5(2.9, \\
4.3)\end{array}$ & 1.0 & $\begin{array}{l}1.8(1.6, \\
2.0)\end{array}$ & $\begin{array}{l}3.2(2.7 \\
3.8)\end{array}$ \\
\hline Qualified manual & 1.0 & $\begin{array}{l}1.6(1.5, \\
1.7)\end{array}$ & $\begin{array}{l}2.8(2.6, \\
3.0)\end{array}$ & 1.0 & $\begin{array}{l}1.6(1.4, \\
1.7)\end{array}$ & $\begin{array}{l}2.9(2.5 \\
3.2)\end{array}$ \\
\hline Unqualified manual & 1.0 & $\begin{array}{l}1.6(1.5, \\
1.8)\end{array}$ & $\begin{array}{l}2.8(2.6, \\
3.1)\end{array}$ & 1.0 & $\begin{array}{l}1.1(1.1 \\
1.1)\end{array}$ & $\begin{array}{l}2.9(2.7 \\
3.1)\end{array}$ \\
\hline Other & 1.0 & $\begin{array}{l}1.3(0.9 \\
1.8)\end{array}$ & $\begin{array}{l}2.5(1.8 \\
3.6)\end{array}$ & 1.0 & $\begin{array}{l}1.1(1.1 \\
1.1)\end{array}$ & $\begin{array}{l}2.9(2.5 \\
3.4)\end{array}$ \\
\hline
\end{tabular}

Table 4 Age standardised mortality rates (MR) per 100000 person years among men and women aged 16 years and above, by socioeconomic group and self rated health at the time of interview. Absolute risk differences between respondents stating poor versus good health

\begin{tabular}{lclll}
\hline & $\begin{array}{l}\text { Overall } \\
\text { mortality } \\
\text { rate/100 }\end{array}$ & $\begin{array}{l}\text { MR among } \\
\text { respondents } \\
\text { stating poor } \\
\text { health }\end{array}$ & $\begin{array}{l}\text { MR among } \\
\text { respondents } \\
\text { stating good } \\
\text { health }\end{array}$ & $\begin{array}{l}\text { MR risk } \\
\text { difference } \\
\text { poor/good } \\
\text { health }\end{array}$ \\
\hline Socioeconomic group & & & & \\
Men & 827 & 2154 & 629 & 1525 \\
$\quad$ Higher non-manual & 820 & 2382 & 679 & 1703 \\
Intermediate non-manual & 878 & 2132 & 656 & 1476 \\
$\quad$ Lower non-manual & 990 & 1992 & 757 & 1235 \\
$\quad$ Qualified manual & 1077 & 2276 & 791 & 1485 \\
$\quad$ Unqualified manual & 1289 & 2491 & 1088 & 1403 \\
$\quad$ Other & 506 & 1423 & 406 & 1017 \\
Women & 450 & 1288 & 343 & 944 \\
$\quad$ Higher non-manual & 519 & 1369 & 380 & 989 \\
Intermediate non-manual & 616 & 1375 & 447 & 928 \\
$\quad$ Lower non-manual & 620 & 1279 & 444 & 835 \\
Qualified manual & 697 & 1670 & 514 & 1156 \\
$\quad$ Unskilled manual & & & & \\
$\quad$ Other & & & & \\
\hline
\end{tabular}

among persons aged 25-34 years, and thereafter declined with age and with increasing absolute mortality rates. However, the mortality rate ratio between persons reporting poor versus good health was lower among persons aged 16-24 years than among persons aged 25-34 years. There was a similar age pattern but lower mortality rate ratios among respondents stating fair health compared with those stating good health (table 2).

Men stating poor health had a significantly higher mortality rate ratio compared with men stating good health, in all socioeconomic groups. Rate ratios were higher in the higher non-manual socioeconomic group than in the two manual socioeconomic groups. Intermediate and lower non-manual men stating poor health had a mortality rate ratio in between that of manual and higher non-manual men. The pattern was similar among women, with higher and intermediate non-manual women stating poor health having the highest mortality rate ratios compared with the other socioeconomic groups (table 3 ).

The mortality rate ratio among men with fair health was significantly higher than among men with good health in all socioeconomic groups except for the group "other". The highest rate ratio was seen among lower nonmanual men $(R R=2.2)$. The mortality rate ratios among higher and intermediate nonmanual men reporting fair health were higher than that among manual men. Women reporting fair health had increased mortality rate ratios compared with women reporting good health in all socioeconomic groups. Rate ratios were lower among unqualified and qualified manual women compared with women in other socioeconomic groups (table 3 ).

Age standardised mortality rates and absolute risk differences in mortality rates were calculated for men and women by self rated health and by socioeconomic group. There was a socioeconomic gradient in mortality among men and women, overall and among men stating good and poor health at the time of the interview. The absolute risk difference in mortality rates, among both men and women, between those stating good or poor health, however, was similar across the socioeconomic groups (table 4).

Stratifying for limiting longstanding illness, the increased risk of death among men and women reporting poor health compared with those reporting good health was similar among those with and those without a limiting longstanding illness. A similar pattern, but with lower mortality rate ratios, was seen among respondents with and without a limiting longstanding illness stating fair health. There were no significant differences between men and women. However, age standardised mortality rates were considerably higher among persons with limiting longstanding illness than among those with no limiting longstanding illness (table 5).

The risk of death was significantly higher among persons reporting poor health than in persons reporting good health in all time periods of follow up. Rate ratios were higher in periods less than two years than in longer follow up periods. Respondents reporting fair health also had a significantly increased risk of death compared with respondents reporting good health in all periods of follow up. The estimates in table 6 are age adjusted.

Table 5 Age standardised mortality rates (MR) per 100000 person years and age adjusted mortality rate ratios (RR) with 95\% confidence intervals among men and women aged 16 years and above, with and without limiting longstanding illness and with poor and good self rated health at the time of interview

\begin{tabular}{lllll}
\hline & $\begin{array}{l}\text { MR among } \\
\text { respondent } \\
\text { stating poor } \\
\text { health }\end{array}$ & $\begin{array}{l}\text { MR among } \\
\text { respondents } \\
\text { stating good } \\
\text { health }\end{array}$ & $\begin{array}{l}\text { MR risk } \\
\text { difference }\end{array}$ & $\begin{array}{l}\text { Mortality RR among } \\
\text { respondents stating poor } \\
\text { versus good health (95\% } \\
\text { CI) }\end{array}$ \\
\hline $\begin{array}{l}\text { Men } \\
\quad \text { with limiting longstanding illness }\end{array}$ & 2721 & 1305 & 1416 & $2.4(2.2,2.5)$ \\
$\quad \begin{array}{l}\text { without limiting longstanding illness } \\
\begin{array}{l}\text { Women } \\
\quad \text { with limiting longstanding illness }\end{array}\end{array}$ & 1563 & 701 & 863 & $2.2(1.8,2.6)$ \\
$\quad$ without limiting longstanding illness & 1600 & 784 & 816 & $2.4(2.2,2.5)$ \\
\hline
\end{tabular}


Table 6 Rate ratio (RR) of mortality over time (with 95\% confidence intervals) among respondents with fair or poor health in relation to respondents with good health, men and women (adjusted for age)

\begin{tabular}{|c|c|c|c|c|c|c|}
\hline \multirow[b]{2}{*}{ Follow up time } & \multicolumn{3}{|l|}{ Men } & \multicolumn{3}{|l|}{ Women } \\
\hline & $\begin{array}{l}\text { Good health } \\
R R\end{array}$ & Fair health $R R$ & Poor health $R R$ & $\begin{array}{l}\text { Good health } \\
R R\end{array}$ & Fair health $R R$ & Poor health RR \\
\hline$<2$ years & 1.0 & $2.0(1.8,2.3)$ & $3.0(2.6,3.5)$ & 1.0 & $2.4(2.0,2.8)$ & $4.0(3.2,4.7)$ \\
\hline $2-4$ years & 1.0 & $1.6(1.5,1.8)$ & $2.1(1.9,2.4)$ & 1.0 & $1.6(1.4,1.7)$ & $2.3(2.0,2.5)$ \\
\hline $5-9$ years & 1.0 & $1.5(1.4,1.6)$ & $2.1(1.9,2.3)$ & 1.0 & $1.4(1.3,1.5)$ & $2.1(1.9,2.3)$ \\
\hline $10+$ years & 1.0 & $1.5(1.4,1.6)$ & $1.9(1.7,2.1)$ & 1.0 & $1.4(1.3,1.5)$ & $2.0(1.8,2.2)$ \\
\hline
\end{tabular}

\section{Discussion}

Our results show a strong association between poor self rated health and an increased risk of subsequent mortality in the Swedish adult population. In addition, a dose-response relation was found-that is, a stronger relation among respondents stating their health was poor than among those whose health was fair-compared with respondents reporting good health at the time of the interview. However, the risk of death was significantly increased also among those with fair health. There were no significant differences between men and women. The relation was stronger in younger than in older age groups and the increased risk of death among persons with fair and poor health was statistically significant also for periods of follow up of 10 years and more. Kaplan and Camacho found a higher age adjusted relative risk for mortality among women (RR 5.10) than among men (RR 2.33) in the US, and that the association between perceived health and mortality was not limited in time, but persisted through the nine year follow up time. ${ }^{5}$ However, in a review of studies of self rated health and mortality, five out of the seven studies that estimated risk ratios separately for men and women found stronger effects for men.?

In a study from Finland, perceived health levels were found mainly to reflect underlying disease burden. ${ }^{9}$ In our study the relative association between self rated health and mortality was similar among men and women with and without a limiting longstanding illness. However, the absolute mortality rates were higher among persons with a limiting longstanding illness than among persons without illness, and the mortality risk differences between persons with poor and good health were almost twice as high among persons with a limiting longstanding illness as among those without a limiting longstanding illness. Among persons with a limiting longstanding illness the risk ratios for mortality were higher for persons reporting good health than for those reporting fair and poor health (data not shown).

The relation between less than good self rated health and risk of death appeared stronger in relative terms in higher than in lower socioeconomic groups, but in absolute terms the risk difference between mortality rates among respondents reporting poor and good health was similar across the socioeconomic groups, within each sex. Thus, the different relation of self rated health and mortality in relative terms observed between socioeconomic groups may be attributable to differing base levels of mortality. Added to the higher base level of mortality of manual workers, the relative significance of poor self rated health to mortality may seem weaker among manual men than among higher and intermediate nonmanual men. However, the similarity in absolute mortality risk differences by self rated health across socioeconomic group would suggest that the predictive value of the measure does not differ appreciably by socioeconomic group. In other words, there was effect modification by socioeconomic group of the relation between self rated health and mortality in relative, but not in absolute, terms. The trend was similar concerning the relation of poor self rated health and mortality with respect to age - the relative relation seemed stronger in younger ages where absolute mortality rates were lower. This may be one explanation for the different observations concerning the predictive value of self rated health for mortality in different settings. However, the mortality risk difference between respondents stating poor health and respondents stating good health was twice as high among men and women with a limiting longstanding illness as among persons without a limiting longstanding illness. Yet, in relative terms the rate ratios between persons reporting poor and good health were similar among men and women with and without limiting longstanding illness. This finding does not support the conclusion that the relative relation would be stronger where absolute mortality rates are lower; however, it does not contradict the finding that poor self rated health is associated with increased risk of subsequent death, also among persons with a limiting longstanding illness.

\section{LIMITATIONS OF THE STUDY}

The question on self rated health that we have used has only three response options. In 1996/97 the ULF survey uses a question on self rated health with five response options. However, our study concerns mortality during follow up in relation to reported self rated health during the survey, and respondents to the survey in 1996/97 had very short follow up with regard to subsequent mortality. We therefore grouped the five response options of respondents in these years into the three categories that were used for the other survey years. The prevalence of fair and poor self rated health obtained in this manner for respondents of the 1996/97 survey was similar to that for the other survey years, overall and across socioeconomic groups. A question with five response options might have increased the contrast in "exposure" and enabled a more detailed study of dose-response patterns between self rated 
health and mortality. As our study is based on secondary analysis of data collected for purposes other than this study, the choice of survey question was beyond our control. Another shortcoming of the study is that there were no data on children and adolescents below the age of 16 years. Therefore, it should be underlined that the results cannot be generalised to age groups not included in the study. However, for the age groups and other subgroups included in the study, the survey sample has been selected to represent the adult Swedish population.

In conclusion, this study has shown that self rated health is a powerful predictor of mortality in Sweden in different socioeconomic groups, among men and among women, in different age groups, over time and among persons with and without a limiting longstanding illness. The relation between poor self rated health and subsequent mortality seemed stronger in relative terms in groups who have lower absolute mortality levels (for example, younger persons and persons in higher socioeconomic groups), but the absolute mortality risk difference between persons stating poor and good health was similar across socioeconomic groups. The results suggest that self rated health has a similar predictive ability in different socioeconomic groups, and that it may be a useful simple outcome measure. Further studies should investigate the predictive value of self rated health for subsequent death attributable to different specific causes of death.

Funding: none.

Conflicts of interest: none.

1 Bjorner JB, Kristensen TS, Orth-Gomér K, et al. Self-rated health. A useful concept in research, prevention and clinical medicine. Stockholm: Swedish Council for Planning and Coordination of Research, 1996.

2 Kunst AE, Geurts JJM, van den Berg J. International variations in socioeconomic inequalities in self reported health. 7 Epidemiol Community Health 1995;49:117-23.

3 Sundquist J, Johansson SE. Self reported poor health and low educational level predictors for mortality: a population based follow up study of 39156 people in Sweden. $\mathcal{F}$ Epidemiol Community Health 1997;51:35-40.

$4 \mathrm{McGee}$ DL, Liao Y, Cao G, et al. Self-reported health status and mortality in a multiethnic US cohort. Am $\mathcal{F}$ Epidemiol 1999;149:41-46.

5 Kaplan GA, Camacho T. Perceived health and mortality: a nine-year follow-up of the human population laboratory cohort. Am f Epidemiol 1983;117:293-304.

6 Mossey JM, Shapiro E. Self-rated health: a predictor of mortality among the elderly. Am F Public Health 1982;72: 800-8.

7 Idler EI, Benyamini Y. Self-rated health and mortality: a review of twenty-seven community studies. F Health Soc Behaviour 1997;38:21-37.

8 Murray CJL, Chen L. Understanding morbidity change. In:Chen L, Kleinman A, Ware NC, eds. Health and social change in international perspective. Boston: Harvard University Press, 1994:87-114.

9 Appels A, Bosma H, Grabauskas V, et al. Self-rated health and mortality in a Lituanian and a Dutch population. Soc Sci Med 1996;42:681-9.

10 Moller L, Kristensen TS, Hollnagel H. Self rated health as a predictor of coronary heart disease in Copenhagen, Denmark. F Epidemiol Community Health 1996;50:423-8.

11 Miilunpalo S, Vuori I, Oja P, et al. Self-rated health status as a health measure: the predictive value of self-reported health status on the use of physician services and on mortality in the working-age population. $f$ Clin Epidemiology 1997;50:517-28.

12 Kaplan GA, Goldberg DE, Everson SA, et al. Perceived health status and morbidity and mortality: evidence from the Kuopio Ischaemic Heart Disease Risk Factor Study. Int f Epidemiol 1996;25:259-65.

13 Statistics Sweden. Nonresponse barometer no 15. Stockholm: Statistics Sweden, 2000. (R\&D Report 2000:3, in Swedish)

14 Statistics Sweden. Yrkesklassificeringar i FoB 85 enligt Nordisk yrkesklassificering (NYK) och Socioekonomisk indelning SEI). Occupations in 1985 (FoB 85) according to Nordic standard occupational classification and Swedish socio-economic classification. Reports on Statistical Co-ordination 1989:5. Stockholm: Statistics Sweden, 1989.

15 Armitage P, Colton T, eds. Encyclopedia of biostatistics. Chichester: Wiley, 1998

16 Cox DR. Regression models and life tables. Fournal of the Royal Statistical Society 1972;34:187-220. 